\title{
Ongoing High Incidence and Case-Fatality Rates for Invasive Listeriosis, Germany, 2010-2019
}

Hendrik Wilking, Raskit Lachmann, Alexandra Holzer, Sven Halbedel, Antje Flieger, Klaus Stark

We used 10 years of surveillance data to describe listeriosis frequency in Germany. Altogether, 5,576 cases were reported, $91 \%$ not pregnancy associated; case counts increased over time. Case-fatality rate was $13 \%$ in non-pregnancy-associated cases, most in adults $\geq 65$ years of age. Detecting, investigating, and ending outbreaks might have the greatest effect on incidence.

Tisteria monocytogenes infections are primarily foodLborne and cause gastrointestinal disease or invasive syndromes among infected persons (1). Because $L$. monocytogenes is an intracellular pathogen and because invasive listeriosis is the primary manifestation in diagnosed listeriosis, persons with deficient cell-mediated immunity are at increased risk for its symptoms, including sepsis and meningitis. In addition, infection during pregnancy can lead to chorioamnionitis and fetal infection that can result in miscarriage and stillbirth even 2 months after the mother is exposed. One study found that $44 \%$ of patients with non-pregnancyassociated (NPA) listeriosis in Germany had received immunosuppressive therapy $\leq 3$ months before illness onset and another $28 \%$ had a coexistent immunocompromising illness, such as diabetes (2). Testing for bacteria in blood cultures or cerebrospinal fluid (CSF) is recommended for diagnosis.

Listeria is ubiquitous in the environment and can produce biofilms in the food production environment and thus contaminate ready-to-eat (RTE) products, which are typically consumed raw or without further processing. Listeria species grow during shelf life, even at low temperatures, and multiply to concentration levels that make invasive listeriosis and outbreaks more

Author affiliations: Department for Infectious Disease

Epidemiology of the Robert Koch Institute, Berlin, Germany (H. Wilking, R. Lachmann, A. Holzer, K. Stark); Department for Infectious Diseases of the Robert Koch Institute, Wernigerode, Germany (S. Halbedel, A. Flieger)

DOI: https://doi.org/10.3201/eid2709.210068 likely. For these reasons, it is suspected that L. monocytogenes exposure is very common but the disease rare. However, in recent years several large outbreaks have been reported in Germany (3-7).

\section{The Study}

We analyzed mandatory notification data about invasive listeriosis cases in Germany during 2010-2019 to describe time trends, case-fatality rates, demographic distribution, clinical and diagnostic characteristics, and geographic trends (Appendix, https://wwwnc. cdc.gov/EID/article/27/9/21-0068-App1.pdf). In total, 5,576 listeriosis cases were reported during the 10year study period; 5,064 (91\%) of those were NPA and 486 (9\%) were pregnancy associated, 241 in mothers and 245 in newborns. Information on disease manifestation was not transmitted for 26 cases. The lowest annual incidence was in 2011 (0.41/100,000 residents) and the highest in 2017 (0.93/100,000 residents); the average for 2010-2019 was 0.69/100,000 residents. We observed a steady increase in cases during 20112017, but incidence in 2019 was lower than in previous years. Exceptionally high numbers were reported in the third quarters of 2016, 2017, and 2018 (Figure 1).

Among the 5,064 NPA listeriosis case-patients, $2,032(40 \%)$ were female and 3,855 (76\%) were $\geq 65$ years of age (Table 1). Listeriosis among adolescents and children other than newborns is rare (37 cases). Incidence in adults $18-44$ years of age is $<0.1 / 100,000$ residents, in contrast with incidence among adults $\geq 85$ years of age: $3.99 / 100,000$ residents for men and $2.08 / 100,000$ residents for women. Annual median age of case-patients increased steadily from 72 years of age in 2010 to 77 years of age in 2019.

Sources for testing samples included CSF (657, $13 \%)$, blood $(4,097,81 \%)$, and material from other usually sterile sites $(274,5 \%)$ (Table 2$)$. A significantly higher proportion of L. monocytogenes was detected in CSF among adults $18-64$ years of age $(24 \%)$ than among those $\geq 65$ years of age $(9 \%)(p<0.01)$; for most 


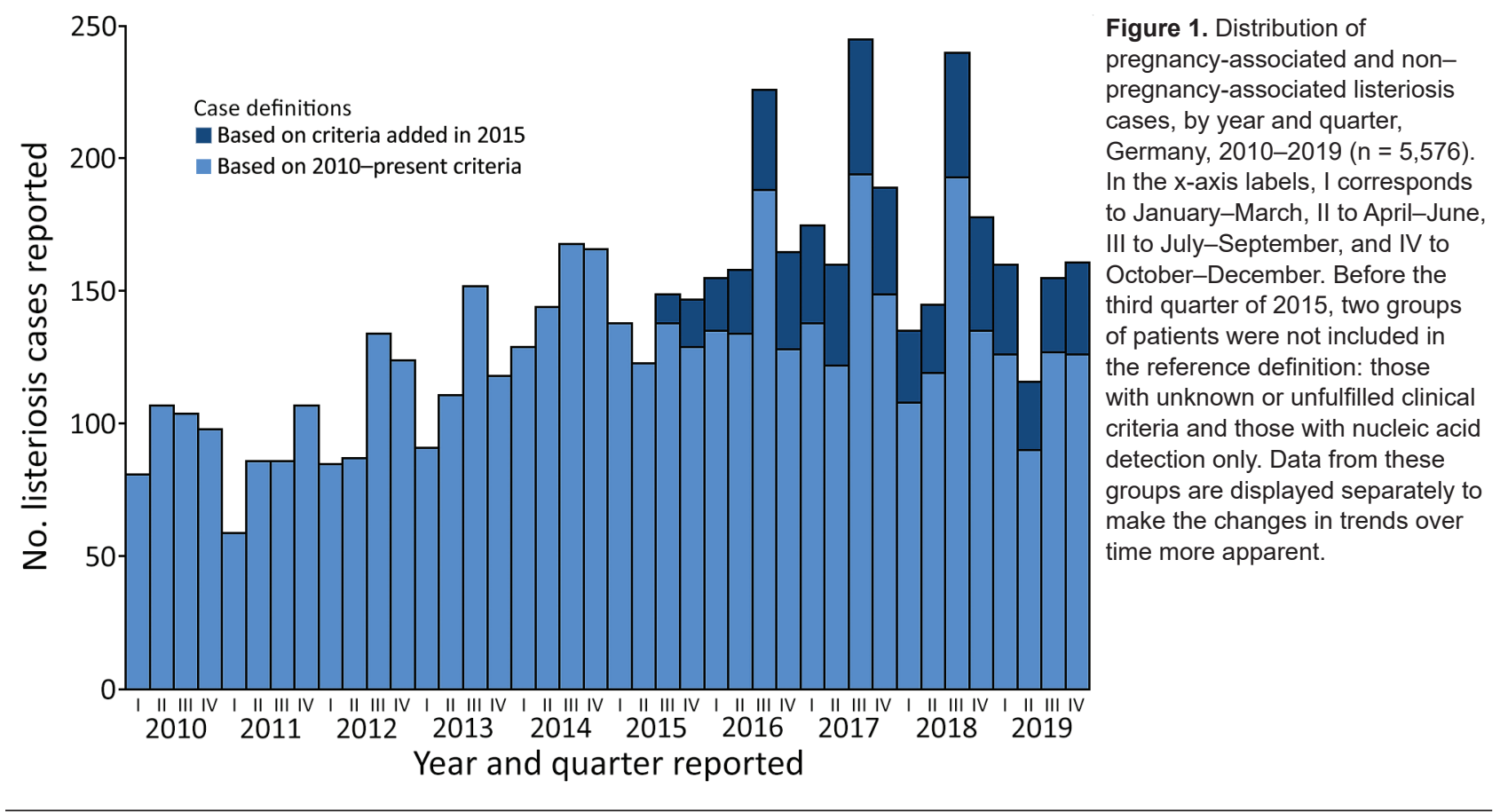

case-patients $\geq 65$ years of age, the isolate was detected from blood. Most NPA case-patients (95\%) were hospitalized; we found no differences among age groups $(p=0.689)$. Altogether, 658 NPA case-patients have been reported deceased. The case-fatality rate for NPA cases was $13 \%$, significantly higher among patients $\geq 65$ years of age (14\%) than among those 18-64 years of age $(10 \%$; $<<0.001)$. Listeriosis was the main cause of death for $324(49 \%)$ of NPA case-patients and a contributing factor for $280(43 \%)$. NPA casefatality rates increased over the 10-year study period, but mainly because of an increase in listeriosis casepatients who died from causes other than listeriosis (Figure 2). For 54 (8\%) deceased case-patients, causeof-death information was missing. Of 301 pregnancyassociated cases, $50 \%$ were confirmed from blood cultures and $54 \%$ from samples of newborn, stillborn, or maternal tissues (in some cases, both). A total of 32 fetal losses and 26 neonatal deaths resulted in a casefatality rate of $19 \%$ for pregnancy-associated cases.

\section{Conclusions}

The aging of the population of Germany as a result of demographic shifts that will continue in the coming years may partially explain the increase in listeriosis cases and the median age of patients. In addition, factors related to the foodborne nature of the disease and an increase in exposure to Listeria must be presumed; it is possible that people eat more RTE food or that RTE food is more likely to become contaminated, although only singlecase findings of L. monocytogenes $>100 \mathrm{CFU} / \mathrm{g}$ have been detected in RTE foods in recent years (8).

\begin{tabular}{|c|c|c|c|c|c|c|}
\hline Patient age, y & $\begin{array}{c}\text { No. male } \\
\text { case-patients }\end{array}$ & $\begin{array}{c}\text { Incidence among } \\
\text { male case-patients }\end{array}$ & $\begin{array}{c}\text { No. female } \\
\text { case-patients }\end{array}$ & $\begin{array}{c}\text { Incidence among } \\
\text { female case-patients }\end{array}$ & $\begin{array}{c}\text { Overall no. } \\
\text { cases }\end{array}$ & $\begin{array}{c}\text { Overall } \\
\text { incidence }\end{array}$ \\
\hline Total & 3,029 & 0.74 & 2,032 & 0.48 & 5,061 & 0.61 \\
\hline$\leq 17$ & 15 & 0.02 & 22 & 0.03 & 37 & 0.03 \\
\hline $18-44$ & 84 & 0.06 & 87 & 0.07 & 171 & 0.06 \\
\hline $45-49$ & 56 & 0.21 & 37 & 0.14 & 93 & 0.18 \\
\hline $50-54$ & 120 & 0.35 & 68 & 0.20 & 188 & 0.28 \\
\hline $55-59$ & 195 & 0.58 & 100 & 0.30 & 295 & 0.44 \\
\hline $60-64$ & 280 & 1.01 & 145 & 0.51 & 425 & 0.75 \\
\hline $65-69$ & 389 & 1.68 & 207 & 0.81 & 596 & 1.23 \\
\hline $70-74$ & 509 & 2.96 & 295 & 1.51 & 804 & 2.19 \\
\hline $75-79$ & 612 & 3.53 & 371 & 1.73 & 983 & 2.54 \\
\hline $80-84$ & 452 & 3.30 & 369 & 1.92 & 821 & 2.49 \\
\hline$\geq 85$ & 317 & 3.99 & 331 & 2.08 & 648 & 2.71 \\
\hline
\end{tabular}

*Incidence is given as no. cases/100,000 residents. 
Table 2. Clinical characteristics of notified cases of invasive listeriosis, Germany, 2010-2019*

\begin{tabular}{|c|c|c|c|c|c|}
\hline \multirow[b]{2}{*}{ Characteristic } & \multirow{2}{*}{$\begin{array}{c}\text { Pregnancy-associated, } \\
\text { no. }(\%) \text { cases }\end{array}$} & \multicolumn{4}{|c|}{ Non-pregnancy-associated, no. (\%) cases } \\
\hline & & Children/adolescents $<18 \mathrm{y}$ & Adults $18-64$ y & Adults $\geq 65$ y & Total \\
\hline Total & $301(100)$ & $37(100)$ & $1,172(100)$ & $3,855(100)$ & $5,064(100)$ \\
\hline \multicolumn{6}{|l|}{ Sex } \\
\hline $\begin{array}{l}F \\
M\end{array}$ & $\begin{array}{c}301(100) \\
0\end{array}$ & $22(59)$ & $437(37)$ & $1,573(41)$ & $2,032(40)$ \\
\hline \multicolumn{6}{|l|}{ Isolate source† } \\
\hline Cerebrospinal fluid & $6(2)$ & $21(57)$ & $277(24)$ & $359(9)$ & $657(13)$ \\
\hline Blood & $152(50)$ & $15(41)$ & $800(68)$ & $3,282(85)$ & $4,097(81)$ \\
\hline Other sterile site & NA & $1(3)$ & $87(7)$ & $186(5)$ & $274(5)$ \\
\hline Birth setting $\ddagger$ & $162(54)$ & NA & NA & NA & $\mathrm{NA}$ \\
\hline \multicolumn{6}{|l|}{ Severity } \\
\hline Hospitalization§ & $253(84)$ & $36(97)$ & $1,064(95)$ & $3,535(95)$ & $4,635(92)$ \\
\hline Death or fetal loss I & $58(19)$ & $0 \#(0)$ & 113\# (10) & $545 \#(14)$ & $658 \#(13)$ \\
\hline \multicolumn{6}{|c|}{$\begin{array}{l}\text { *NA, not applicable } \\
\text { tWhen Listeria monocytogenes is isolated from multiple anatomic sites, only a single site is reported (priority order: cerebral spinal fluid, blood, other } \\
\text { sterile site, and birth setting). } \\
\text { †Either from a newborn, fetus, stillborn or from maternal tissue (placental tissue, uterus, cervix). } \\
\text { \$Hospitalizations among singleton neonates for } 224 \text { pregnancy-associated cases. } \\
\text { |2 } 26 \text { neonatal deaths, } 32 \text { fetal losses. Among all pregnancy-associated cases } 161 \text { premature births were recorded. } \\
\text { \#lnformation available for } 4,989 / 5,064(99 \%) \text { of notified cases. }\end{array}$} \\
\hline
\end{tabular}

The additional case numbers in some quarters of the year (Figure 1) were all associated with large-scale outbreaks $(3,6)$. Successfully identifying and controlling large outbreaks, especially after whole-genome sequencing-based surveillance was introduced, possibly explains why the trend in increases ended after 2017 (9). Overall listeriosis incidence in Germany is higher than in all neighboring countries except Denmark (10). In Europe, incidence is generally higher in countries in Scandinavia and the Baltic region and lower in the United Kingdom and Ireland (10).

As is the case for other pathogens, listeriosis surveillance results in underascertainment, although it is difficult to quantify by how much. Listeria sepsis cannot be clinically distinguished from other bacterial sepsis, and isolating Listeria or detecting DNA from blood samples is often impossible because bacteremia is absent or intermittent. In addition, laboratory diagnostic testing is often not performed after abortions or stillbirths or for persons who are found dead.

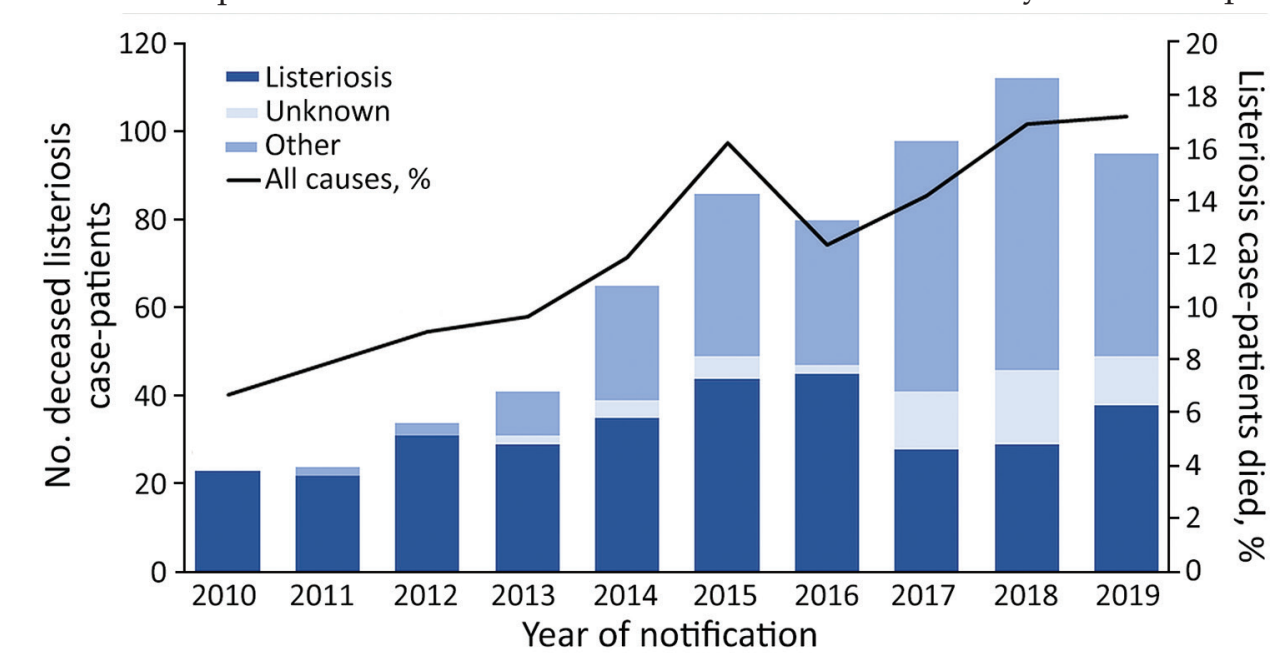

Listeriosis has one of the highest case-fatality rates among notifiable infectious diseases. The casefatality rate for Germany in this study is surprisingly lower than that for Europe overall, 15.6\% (10), and for the United States, 21\% (11). A cohort study in France reported a 3-month death rate of $45 \%$ for bacteremia from Listeria infection and 30\% for neurolisteriosis cases (12). Lower rates may be partially explained by well-equipped intensive care units, but it is more likely that many deaths occurring long after original disease notifications were not reported to public health departments.

Of interest, surveillance data from the United States indicate more listeriosis among women and higher proportions of pregnancy-associated cases $(11,13)$ than in our study. One explanation might be that, in Germany, meat products, more often eaten by men, constitute prominent outbreak vehicles $(3,4,6,7)$, whereas in the United States several outbreaks were caused by nonanimal products or cheese (11).

Figure 2. Distribution of nonpregnancy-associated listeriosis cases $(n=5,061)$ in which the patients died $(n=658)$ and casefatalities by year and cause of death, Germany, 2010-2019. Black line indicates percentage of infected persons who died. 
Systematic whole-genome sequence typing of Listeria isolates from patients would aid in detecting and investigating outbreaks. These molecular data should be integrated into surveillance data from cases notifications and isolates found in food. Combining data from molecular surveillance with epidemiologic investigations would help systematically identify and eliminate contaminated sources, which might have the greatest effect on reducing the overall burden of listeriosis and thus flattening its high incidence curve. Two factors interact to have the greatest influence on personal risk profiles. Listeriosis is highly associated with age, which is affirmed in our study, and strongly associated with documented immunosuppressive conditions (2). Persons with these risk profiles should be targeted in information campaigns about how to safely consume RTE foods and avoid certain types of cheeses, meat products, and smoked or graved (cured) fish products. All food producers, and especially those providing food for immunocompromised patients in healthcare facilities, should take steps to minimize L. monocytogenes hazards when producing, selecting, and preparing food.

\section{Acknowledgment}

We thank all stakeholders in listeriosis surveillance, especially the local and federal state authorities in Germany and at the Robert Koch Institute in Berlin.

\section{About the Author}

Dr. Wilking is an epidemiologist and deputy head of the Unit for Gastrointestinal Infections, Zoonoses and Tropical Infections at Robert Koch Institute in Berlin, Germany. He has a strong interest in foodborne diseases.

\section{References}

1. Allerberger F, Wagner M. Listeriosis: a resurgent foodborne infection. Clin Microbiol Infect. 2010;16:16-23. https:/ / doi.org/ 10.1111/j.1469-0691.2009.03109.x

2. Preußel K, Milde-Busch A, Schmich P, Wetzstein M, Stark K, Werber D. Risk factors for sporadic non-pregnancy associated listeriosis in Germany - immunocompromised patients and frequently consumed ready-to-eat products. PLoS One. 2015;10:e0142986. https:/ / doi.org/10.1371/ journal.pone.0142986

3. Halbedel S, Wilking H, Holzer A, Kleta S, Fischer MA, Lüth S, et al. Large nationwide outbreak of invasive listeriosis associated with blood sausage, Germany, 20182019. Emerg Infect Dis. 2020;26:1456-64. https://doi.org/10.3201/eid2607.200225

4. Kleta S, Hammerl JA, Dieckmann R, Malorny B, Borowiak M, Halbedel S, et al. Molecular tracing to find source of protracted invasive listeriosis outbreak, southern Germany, 2012-2016. Emerg Infect Dis. 2017;23:1680-3. https://doi.org/10.3201/eid2310.161623

5. Lachmann R, Halbedel S, Adler M, Becker N, Allerberger F, Holzer A, et al. Nationwide outbreak of invasive listeriosis associated with consumption of meat products in health care facilities, Germany, 2014-2019. Clin Microbiol Infect. 2021;27:1035.e1-5. https:// doi.org/10.1016/j.cmi.2020.09.020

6. Lüth S, Halbedel S, Rosner B, Wilking H, Holzer A, Roedel A, et al. Backtracking and forward checking of human listeriosis clusters identified a multiclonal outbreak linked to Listeria monocytogenes in meat products of a single producer. Emerg Microbes Infect. 2020;9:1600-8. https:/ / doi.org/10.1080/22221751.2020.1784044

7. Ruppitsch W, Prager R, Halbedel S, Hyden P, Pietzka A, Huhulescu S, et al. Ongoing outbreak of invasive listeriosis, Germany, 2012 to 2015. Euro Surveill. 2015;20:20. https:/ / doi.org/10.2807/1560-7917.ES.2015.20.50.30094

8. Bundesamt für Verbraucherschutz und Lebensmittelsicherheit (BVL). Zoonoses monitoring [German]. 2020 [cited 2021 June 8]. https://www.bvl.bund.de/DE/Arbeitsbereiche/ 01_Lebensmittel/01_Aufgaben/02_AmtlicheLebensmittelueberwachung/06_ZoonosenMonitoring/lm_zoonosen_ monitoring_node.html

9. Halbedel S, Prager R, Fuchs S, Trost E, Werner G, Flieger A. Whole-genome sequencing of recent Listeria monocytogenes isolates from Germany reveals population structure and disease clusters. J Clin Microbiol. 2018;56:e00119-18. https://doi.org/10.1128/JCM.00119-18

10. European Food Safety Authority and European Centre for Disease Prevention and Control. The European Union One Health 2018 zoonoses report. 2019 [cited 2021 June 8]. https://www.ecdc.europa.eu/en/publications-data/ european-union-one-health-2018-zoonoses-report

11. Centers for Disease Control and Prevention (CDC). Vital signs: Listeria illnesses, deaths, and outbreaks - United States, 2009-2011. MMWR Morb Mortal Wkly Rep. 2013;62:448-52.

12. Charlier C, Perrodeau É, Leclercq A, Cazenave B, Pilmis B, Henry B, et al.; MONALISA study group. Clinical features and prognostic factors of listeriosis: the MONALISA national prospective cohort study. Lancet Infect Dis. 2017;17:510-9. https://doi.org/10.1016/S1473-3099(16)30521-7

13. European Centre for Disease Prevention and Control. Listeriosis annual epidemiological report for 2017. 2020 [cited 2021 June 8]. https:/ / www.ecdc.europa.eu/sites/ default/files/documents/listeriosis-annual-epidemiologicalreport-2017.pdf

Address for correspondence: Hendrik Wilking, Robert Koch Institute, Seestraße 10, 13353 Berlin, Germany; email: WilkingH@rki.de 